ISSN 0103-7013

Psicol. Argum., Curitiba, v. 28, n. 61, p. 127-134 abr./jun. 2010 Licenciado sob uma Licença Creative Commons

\title{
A ESCOLARIZAÇÃO DE CRIANÇAS E DE ADOLESCENTES COM PROBLEMAS PSÍQUICOS GRAVES NO BRASIL E NA FRANÇA: Algumas observações
}

\author{
School inclusion of children and adolescents with serious psychological problems in \\ Brazil and in France: Some notes
}

\author{
Maria Cristina Kupfer ${ }^{[a]}$, Bernard Pechberty ${ }^{[b]}$ \\ [a] Psicanalista e professora titular do Instituto de Psicologia da Universidade de São Paulo (USP), São Paulo, SP - Brasil, e-mail: \\ mckupfer@usp.br \\ [b] Psicanalista e professor titular em Ciências da Educação da Universidade de Paris-Descartes, em Paris - França.
}

\begin{abstract}
Resumo
O presente texto é o resultado inicial do balanço de trabalho de duas equipes, a propósito dos temas da terminologia no campo dos problemas psíquicos de crianças incluídas, da formação de professores e do desejo de saber de alunos com problemas psíquicos graves. As duas equipes (o LEPSI, da Faculdade de Educação/Instituto de Psicologia, da Universidade de São Paulo, e CLIOPSY, das Universidades de Paris $\mathrm{V}$ e Paris X) inscrevem-se no campo de pesquisa das intersecções entre a psicanálise e a educação. Em relação à discussão terminológica em torno da designação das "crianças deficientes, com handicap ou com necessidades educativas especiais", os autores optaram por defender a retomada da antiga expressão "problemas psíquicos", para sinalizar a recusa de uma presença massiva do discurso médico na área da educação. No campo do cuidado dirigido aos profissionais da inclusão escolar, os autores consideram imprescindível identificar as condições que vão preservar o educador do burn-out ou da depressão profissional face ao pesado e complexo trabalho de inclusão escolar. Relatam uma pesquisa francesa e outra brasileira em torno desse tema. Finalmente, discorrem sobre o lugar do desejo de saber na escolarização de crianças com problemas psíquicos graves. Conclui-se que, se a escola inclusiva de hoje não for capaz de fazer a pergunta pelo desejo do aluno, teremos que mobilizar educadores, psicanalistas e pesquisadores para renová-la.
\end{abstract}

Palavras-chave: Psicanálise e educação. Problemas psíquicos. Inclusão escolar. Formação de professores. Desejo de saber. 


\begin{abstract}
This is the initial result of the sum-up of the work of two teams. It refers to issues of 1. terminology in the field of the mental health problems of 'children of inclusive education', 2. teacher training and 3. the desire to know of students with serious psychological problems. The two teams (LEPSI, Faculty of Education/Institute of Psychology, University of São Paulo, and CLIOPSY, University of Paris V and Paris X) belong to the research field of the intersections between psychoanalysis and education. In regard to the terminology discussion around the designation of "disabled children, handicapped or with special needs", the authors chose to defend the revival of the old expression "mental problems", in order to signal the rejection of a massive presence of medical discourse in the area of education. In the field of the care for practitioners of inclusive education, the authors consider it essential to identify the conditions that will protect the educator from the 'burn-out' or the professional depression in face of the heavy and complex work of school inclusion. They report a French and a Brazilian studies around that theme. Finally, they discuss the place of the desire to know in the schooling of children with serious psychological problems. It follows that if the inclusive school of today is not able to make questions about the desire to know, we must mobilize educators, psychoanalysts and researchers to work toward a transformation of that school.
\end{abstract}

Keywords: Psychoanalysis and education. Psychological problems. Inclusive education. Teacher training. Desire to know.

Este trabalho inscreve-se em um contexto internacional no qual as crianças e jovens ditos "em situação de handicap mental", na terminologia francesa, ou "com necessidades especiais", na terminologia atualmente empregada no Brasil, são objeto de apostas éticas, políticas, econômicas e educativas importantes. No contexto francês, a lei de 11 de fevereiro de 2005, ou, no brasileiro, a LDB de 1996 e a Resolução de 11 de setembro de 2001 (Brasil, 1996), indicam bem o esforço que fazem esses dois países para equacionar socialmente as diferenças e incluir esses jovens na vida escolar e cotidiana.

Essas iniciativas políticas e educativas se chocam, no entanto, com as dificuldades oriundas dos desafios colocados pela própria inclusão. As pesquisas atuais mostram a necessidade de uma profunda mudança cultural a fim de que a "deficiência", em particular a mental, ou mais precisamente psíquica, encontre seu lugar no seio das sociedades (Gardou, 2009).

Dentro deste amplo campo, o grupo das crianças e jovens com problemas psíquicos graves coloca desafios ainda maiores quando se trata de escolarizá-las, e reclama a atenção dos pesquisadores por três razões. Primeiramente, $38,4 \%$ dessas crianças já estão em escolas na França (Gachet, 2009) e 51,4\% no Brasil (Oliveira, 2009) ${ }^{1}$. Em segundo lugar, a escolarização é a mais importante arma de adaptação social da qual podem servir-se essas crianças e jovens. Ela permite uma inserção social que favorece sua autonomia social, uma melhor qualidade de vida e uma menor dependência da ajuda do Estado. Finalmente, os dois países já oferecem atualmente condições razoáveis para a escolarização de crianças e jovens com problemas psíquicos, mas ambos enfrentam grandes dificuldades para ampliar o alcance de seus programas de inclusão escolar e para preparar educadores implicados nessa escolarização. Mais que isso: França e Brasil têm dado pouca atenção à formação de educadores para o enfrentamento do desafio que é considerar essas crianças e jovens em sua singularidade própria. Nesses dois contextos - o da ampliação de programas e o da formação de educadores - a grande maioria dos profissionais implicados na cena educativa coloca demandas de formação intensiva e específica; esses profissionais afirmam não se sentir suficientemente preparados para exercer suas funções no quadro da inclusão escolar.

Depois de realizar alguns trabalhos de cooperação universitária, dois professores de duas

1 Os números do Ministério da Educação sobre a inclusão de crianças com problemas ou deficiências variadas não separa a categoria dos problemas psíquicos e a coloca dentro da grande categoria das deficiências mentais. Assim, os números aqui colocados não expressam a incidência precisa das crianças com problemas psíquicos e escolarizadas no Brasil. 
equipes, uma francesa e uma brasileira ${ }^{2}$, cujo campo de pesquisa comum é o das intersecções entre a psicanálise e a educação, decidiram escrever um texto em torno de três sub-temas sobre os quais publicaram ou refletiram nos últimos dez anos. O presente texto é o resultado inicial desse primeiro balanço, a propósito dos temas da terminologia, da formação de professores e do desejo de saber de alunos com problemas psíquicos graves

\section{Problemas de terminologia}

No campo do handicap mental, ou dos problemas psíquicos severos, não há homogeneidade terminológica nem teórica. Existe, porém, toda uma literatura que se dedica à crítica de termos que sublinham o caráter deficitário das diferenças (Lajonquière, 2001) em vez de sublinhar simplesmente a distância com relação a uma norma sempre suposta.

Nossas pesquisas comuns levaram-nos à adoção de uma categoria utilizada nos dois países: a de problemaspsíquicos graves, rótulo sob o qual se inscrevem os Transtornos Invasivos do Desenvolvimento (DSM-IV, 1995), ou as psicoses e autismos, na terminologia psicanalítica, ou os distúrbios do espectro autista, na terminologia americana atual.

Os pesquisadores e praticantes que trabalham no campo dos problemas psíquicos graves vêm observando um deslizamento que precisa ser sinalizado: o termo psíquico está gradativamente desaparecendo dos números oficiais no campo do handicap na França, ou das necessidades especiais no Brasil. No entanto, é preciso alertar para o fato de que a vontade de apagar esse termo e de reduzir a dimensão psíquica à cognitiva não facilita a compreensão dos fenômenos em jogo.

A categoria dos problemas psíquicos supõe e leva em conta, de nosso ponto de vista, a necessária hipótese do inconsciente, colocada pela psicanálise. Mas essa abordagem encontra-se atualmente sob fogo cerrado, especialmente no campo das ditas "deficiências".
A recusa da psicanálise está sem dúvida na raiz dessa vontade de fazer desaparecer tal nomenclatura. No entanto, como indica Hochmann (2009, p. 28-29),

os psicanalistas foram, durante muito tempo, os únicos a ocupar-se seriamente das crianças autistas, arrancando-as de um fechamento sem esperanças. [...] Mas, assimilando abusivamente o autismo aos distúrbios do apego, alguns dentre eles incriminaram, sem prova convincente, os pais e singularmente as mães na fabricação do autismo de seus filhos.

Essas "aproximações perigosas" sofreram, segundo ele, um questionamento violento feito por alguns movimentos de famílias de crianças com problemas, "questionamento que tende a arrastar com ele uma crítica global da orientação psicanalítica, ainda que essa última não partilhe dessas aproximações" (Hochmann, 2009, p. 29).

O apagamento da dimensão psíquica nas considerações do campo educativo coloca, no entanto, sérios problemas. Consultando os números recentes fornecidos pelo INRP (Gachet, 2009), observa-se que $80 \%$ das crianças "em situação de handicap" escolarizadas podem estar apresentando algum tipo de distúrbio psíquico ${ }^{3}$. No Brasil, a terminologia Transtornos Invasivos do Desenvolvimento - TID - (DSM-IV, 1995) vem sendo cada vez mais utilizada, denotando um crescimento no número de crianças diagnosticadas ${ }^{4}$, mas esse uso crescente de uma categoria apenas cognitiva sublinha também o fato de que os aspectos psíquicos não estão sendo levados em conta na proporção que eles merecem, tendo em vista a sua incidência sinalizada por pesquisas recentes (Fleitlich-Bilyk \& Goodman, 2004).

A adoção da terminologia "problemas psíquicos" sinaliza ainda a recusa de uma presença massiva do discurso médico na área da educação, que impôs o uso de termos como "distúrbios" ou "transtornos", faz o psicólogo e o psicopedagogo chamarem as crianças de pacientes, exige diagnósticos

2 As equipes são: LEPSI, da Faculdade de Educação/Instituto de Psicologia, da Universidade de São Paulo, e CLIOPSY, das Universidades de Paris V e Paris X.

3 Esse número se obtém se somamos os 38,4\% da categoria “distúrbios psíquicos" aos 43,7\% da categoria “vários distúrbios associados", já que nessa última estão colocadas as crianças que apresentam algum tipo de "distúrbio" de comportamento.

4 Hoje, nos Estados Unidos, fala-se em um autista em cada 150 crianças (CDC, 2007). 
e anamneses, e inunda os trabalhos dessas áreas com sintomas.

A palavra "distúrbio" tem todas as ressonâncias dessa visão da deficiência como doença. Já a palavra "problemas" indica a existência de uma perturbação, ou de um sofrimento, de natureza psíquica, mesmo que ele tenha um fundamento orgânico. Esse sofrimento está sendo indicado pelo sujeito ou por seus pais, e não é necessariamente uma categorização no interior de uma nosografia médica. Pode ser mais impreciso, mas permite melhor aproximação com o singular de cada sujeito.

Assim, a insistência na nomenclatura dos "problemas psíquicos" advém da adoção de uma posição clínica e ética, que considera tais crianças e jovens como sujeitos aptos ao desejo e ao estabelecimento de uma relação possível com os outros.

\section{O cuidado dirigido aos profissionais da inclusão escolar}

No campo da escolarização das crianças e jovens que sofrem de problemas psíquicos, poucas pesquisas trabalham sobre a especificidade das dinâmicas psíquicas mobilizadas nos profissionais em seu trabalho.

No entanto, o foco sobre esse tema se justifica na medida em que é imprescindível identificar as condições que vão preservar o educador do burn-out ou da depressão profissional face ao pesado e complexo trabalho de inclusão escolar.

Essas condições devem facilitar o sentido, a criatividade, o desejo de transmitir e de ensinar face a alunos tão desconcertantes. Devem também facilitar a sustentação dos laços de trabalho e de identificação com as crianças e jovens com problemas psíquicos graves e suas famílias. É preciso acompanhar os educadores na busca de recursos narcísicos que lhes permitam agir, pensar, adaptando-se à singularidade de cada aluno com problemas, sem perder seu lugar de professor e sua relação com o saber ensinar.

As equipes mencionadas no presente trabalho vêm produzindo pesquisas nessa direção. Pode-se afirmar que ambas vêm buscando compreender e analisar os mecanismos de elaboração grupal que podem ser postos em jogo nos diferentes contextos de inclusão escolar e educativa. Esses mecanismos grupais podem ser um auxiliar valioso na identificação dos efeitos nocivos de tais contextos sobre os profissionais envolvidos e, ao mesmo tempo, um lugar para a sua superação. Segue-se um resumo das contribuições recentes das duas equipes no campo dos cuidados dirigidos aos educadores nos dois países.

\section{A pesquisa francesa: A inclusão escolar de adolescentes com problemas psíquicos graves conduzida por equipes médico-educativas}

Essa pesquisa, atualmente em curso na Faculdade de Ciências da Educação da Universidade de Paris V e conduzida por B. Pechberty, focaliza as práticas e as experiências vividas por profissionais e professores confrontados com os adolescentes com problemas psíquicos ou, para usar a terminologia francesa, em situação de handicap mental.

O tratamento desses adolescentes suscita atualmente novas formas de colaboração entre os diferentes profissionais da saúde (médicos, psicólogos, psicomotricistas etc.) da educação (educador especializado, mediador) ou do ensino (professor do ensino regular ou especializado, conselheiro de educação, diretores de escolas), no quadro das leis sobre a igualdade de direitos das pessoas (ditas) deficientes. Poucas pesquisas na França abordam, porém, a particularidade do trabalho desses profissionais e o modo como estão aí implicados. Diferentemente das ditas deficiências físicas, o dito handicap mental atinge a relação com o outro e suscita reações originais, modalidades de defesa e de distanciamento no interior da chamada personalidade profissional (Pechberty, 2007) dos diferentes praticantes.

A pesquisa adota uma abordagem que não separa as dinâmicas subjetivas de suas relações com o ambiente psíquico, social, familiar e escolar, e se coloca na confluência das orientações psicanalíticas de Klein, Winnicott e Lacan. Busca responder às seguintes questões: de que modo o acompanhamento conduzido por profissionais especializados pode ser conciliado com os objetivos de diminuição dos efeitos estigmatizantes dos problemas psíquicos graves? As práticas e as intervenções dos profissionais que comportam lógicas e culturas diferentes são complementares, justapostas ou conflitam dentro do campo da escolarização dos adolescentes com problemas psíquicos?

Três níveis de estudo estão sendo considerados, e reúnem diversos especialistas nessa questão: 
a) o primeiro nível faz aparecer os sentidos múltiplos veiculados pelas experiências singulares dos profissionais, as ressonâncias subjetivas conscientes e inconscientes induzidas pelo trabalho com os adolescentes: representações vividas, transferências e contratransferências mobilizadas;

b) o segundo nível estuda as interações e as histórias dos serviços e dos contextos escolares ou reeducativos nos quais estão implicados o tratamento, a educação e o ensino. Refere-se à psicologia social clínica e busca localizar os mitos de fundação, as relações institucionais e seus efeitos sobre a inclusão;

c) o terceiro nível estuda a evolução das leis, das regulamentações institucionais que estruturam as ações desses profissionais, de uma perspectiva sócio-histórica.

Os primeiros resultados já confirmam a necessidade de interrogar os cruzamentos entre as experiências subjetivas dos profissionais e os tipos de relações institucionais mobilizadas por seu trabalho com esses adolescentes. A análise da complexidade do trabalho nessas situações-limite permite destacar as aproximações e diferenças entre eles, bem como os mecanismos de defesa e de distanciamento utilizados por cada profissional em relação a seu ideal profissional no encontro com jovens com problemas psíquicos graves.

O estudo das ligações dos profissionais entre eles mostrou ainda que os diferentes tipos de colaboração podem entrar em ressonância de modo limitativo ou criativo, dependendo das dinâmicas psíquicas que se colocam em jogo.

\section{A pesquisa brasileira: A formação de professores inclusivos}

A pesquisa brasileira de formação de professores desenvolveu-se no Lugar de Vida, um serviço pertencente à Universidade de São Paulo até 2007, que desenvolveu, desde sua fundação em 1990, uma experiência de acompanhamento em serviço de professores e de tratamento terapêutico e educativo de crianças com problemas psíquicos severos, com o objetivo de promover sua inclusão escolar (Colli \& Kupfer, 2005).

Naquela instituição, o trabalho com a formação de "professores inclusivos" da rede pública é considerado fundamental. "O trabalho de inclusão escolar não pode ser realizado sem a inclusão de professores, já que eles são uma das ferramentas mais importantes na sustentação desse lugar social - a escola - que se pretende oferecer à criança com problemas psíquicos graves" (Kupfer \& Bastos, 2003).

O Lugar de Vida promove uma reunião mensal aberta aos professores da rede pública interessados em discutir suas dificuldades com os alunos incluídos. Tais reuniões são coordenadas pelo Grupo Ponte e o número de educadores oscila em torno de 20 a cada encontro.

A dinâmica dessas reuniões é bastante informal e todos os participantes têm acesso à palavra, após uma breve apresentação inicial. Ao fim da rodada de apresentação é dada a palavra aos professores que trabalham com as crianças do Lugar de Vida para que falem sobre suas dificuldades e inquietações diante dessa criança que está em processo de inclusão na escola regular.

A partir desse trabalho, algumas pesquisas e publicações já foram realizadas (Bastos, 2003; Mena, 2000; Sayão \& Leão, 2000). Esses estudos se orientam por alguns fundamentos teórico-clínicos que servem de base para os trabalhos realizados no Lugar de Vida. Dentre eles, destacamos aqui o instrumento da escuta e a confrontação com o próprio dizer.

a) O instrumento da escuta: observa-se, num primeiro momento, que os professores buscam as reuniões de professores com uma expectativa explícita de que receberão ali algum tipo de 'treinamento' que irá auxiliá-los na tarefa de trabalhar com esses alunos ditos 'diferentes'. Mesmo sendo uma demanda imaginária, o trabalho de escuta feito pela equipe irá propiciar aberturas em outras direções. Ao invés de fornecer respostas que obturem e fechem as interrogações, a equipe sugere que o professor fale de

5 O Grupo Ponte é a equipe responsável, no Lugar de Vida, pela realização das reuniões mensais com professores inclusivos. 
sua experiência e faça interlocução com seus pares; desse modo se inicia uma circulação discursiva que tira o professor do lugar de queixoso e impotente e o coloca na posição de interrogar-se sobre a sua prática escolar.

A equipe do Ponte concluiu que a escuta provoca deslocamentos nas posições subjetivas dos professores em relação à problemática de seus alunos.

b) A confrontação com o próprio dizer: essa experiência de trabalho com professores mostrou ainda que a explicitação das produções discursivas tem como efeito aquilo que Lacan (1958), no texto "A direção do tratamento e os princípios de seu poder", chama de confrontação, marcando o que distingue, radicalmente, essa intervenção de uma interpretação.

Ao discutir a direção do tratamento, Lacan marca a diferença entre aquilo que é da ordem de uma interpretação (que aponta para o fantasma, para o sujeito do desejo) e aquilo que é da ordem de uma confrontação do sujeito com seu próprio dizer. Trata-se de fazê-lo proferir uma formulação articulada, que o leva a ter uma visão, um insight de uma de suas condutas e o leva, portanto, a refletir sobre o que disse. Esse “dizer esclarecedor" possibilita que o professor se dê conta de sua implicação naquilo que, num primeiro momento, era visto como um problema exclusivo da criança e a respeito do qual ele só podia lamentar, queixando-se da falta de recursos e preparo, dele e da escola.

Através dos relatos que o professor é convidado a fazer diante do grupo, vê-se a importância de ele poder resgatar e se apropriar do trabalho que está desenvolvendo com a criança, pois, partindo-se da premissa de que o que se desenvolve no grupo é uma rede de linguagem, essa fala pode assumir novos desdobramentos à medida que o professor se vê confrontado com o seu próprio dizer.

Nota-se que essa escuta que implica o outro em uma confrontação com seu próprio dizer contribui para que se instalem, no lugar das certezas, perguntas e questões referentes às interpretações que os professores dão às atitudes "estranhas" de seus alunos, sendo visíveis os efeitos provocados por esse trabalho de escuta na relação que os professores passam a manter com eles.

\section{O lugar do desejo de saber na escolarização de crianças com problemas psíquicos graves}

Durante colóquio sobre a escolarização de crianças "em situação de handicap" na França, em 2009, uma ouvinte brasileira perguntou a um dos conferencistas como ele havia obtido resultados tão bons no trabalho com uma criança "incluída". A criança parecia bastante desejosa de aprender, apesar de suas dificuldades, por isso o ouvinte queria saber como havia sido construído o desejo de aprender que aquela criança demonstrava ter. A essa pergunta, o conferencista retrucou: "mas minha senhora, o desejo de aprender é inato!" Diga-se, de passagem, que o referido colóquio foi pontilhado de momentos de questionamento sobre a pertinência de utilizar "categorias psicanalíticas como a noção de desejo", já que, segundo participantes do colóquio, elas eram bastante dispensáveis.

A resposta da conferencista é aqui relatada porque representa bem uma posição que marca grande distância em relação à da psicanálise sobre esse assunto: se há algo de inato em relação ao aprender, esse inato não pode se referir ao desejo, mas apenas à ordem da necessidade. Para a psicanálise, não há desejo que não tenha sido construído ao longo da história de um sujeito. Mais ainda, uma criança poderá não ter ainda constituído seu desejo de aprender ou de saber, ainda que reaja a uma necessidade de aprender.

A necessidade de aprender faz parte, sem dúvida, da bagagem biológica de uma criança. Ao chegar ao mundo em situação de desamparo, fruto de sua incontornável dependência do semelhante, é imperioso que ela disponha de mecanismos para aprender a sobreviver e a se tornar autônoma. Mas não é dessa necessidade de aprender que estamos falando. Dessa necessidade a criança autista não está privada; ao contrário, ela aprendeu a comer, a andar, a ir buscar os objetos que lhe agradam. Mas quando o registro em discussão é o da escola e o do conhecimento, não basta a necessidade de aprender.

O desejo de aprender é, para Freud (1905, p. 1207), construído muito cedo.

Na mesma época em que a vida sexual da criança alcança seu primeiro florescimento, o que ocorre do terceiro ao quinto ano, aparecem os primeiros indícios desta atividade, denominada pulsão de saber ou pulsão de investigação [...].A 
pulsão de saber das crianças é atraída - e talvez despertada-pelos problemas sexuais com uma precocidade e intensidade insuspeitadas.

Ou seja, o desejo de saber surge a partir do enfrentamento de questões sexuais. Para Freud, os problemas sexuais e as perguntas que as crianças costumam fazer em torno deles são o reflexo de uma pergunta fundamental, que não será porém proferida jamais. "De onde viemos e para onde vamos?" As origens se referem à sexualidade, e o lugar para onde vamos, à morte. São esses, para Freud, os dois grandes problemas com que se defronta a criança desde muito cedo.

É por não haver respostas para essa pergunta que uma criança se lança no mundo do conhecimento e das produções da cultura. É da falta que nasce o desejo, não se cansa de ensinar a psicanálise. Aplicando-se essa máxima à escola, é porque há uma falta de respostas às questões fundamentais que as crianças, paradoxalmente, se lançam na busca dessas respostas - busca, por isso mesmo, infindável - e aceitam curvar-se à instituição escolar (Kupfer, 1990).

A pergunta pelas origens, não é, além disso, retórica ou filosófica. É libidinal e se articula, portanto, à dimensão pulsional. Mostra que a criança está procurando seu lugar em um antes e um depois, em uma filiação, em uma cadeia geracional.

O desejo de saber, assim colocado, pode ser distinguido da necessidade de aprender, dispositivo biológico que muito cedo dá lugar ao desejo de saber na vida de uma criança. E permite ainda outra distinção: aquela entre demanda de aprender e desejo de aprender. Muitas crianças lançam-se ao mundo das aprendizagens apenas para agradar aos adultos e obter aprovação $0^{6}$. A demanda de aprender não gera, porém, uma verdadeira relação com o saber.

Entre os autores franceses, a tradição de pesquisa em torno da noção clínica de relação com o saber também vem contribuir para a discussão sobre o desejo de saber das crianças e jovens com problemas psíquicos.

Para Beillerot (1989), a relação com o saber, para um sujeito, se refere à necessidade de analisar sua situação, sua posição, sua prática e sua história para lhe atribuir seu próprio sentido. A relação com o saber torna-se então um processo criador de saber, pelo qual um sujeito integra todos os saberes disponíveis e possíveis de seu tempo. Vê-se, nessa concepção, uma concordância com a ideia de que é necessário atribuir um sentido ao saber que está sendo aprendido, e se pode acrescentar que esse sentido é, freudianamente falando, aquele que articula o sujeito com suas próprias origens. Além disso, Beillerot se refere a um saber que se define como um processo criador. Assim, a transmissão de conhecimento, vista dessa perspectiva, implica uma construção da qual o sujeito é necessariamente parte integrante. "A relação com o saber não nomeia o saber, mas a ligação de um sujeito com um objeto" (Beillerot, 1989, p. 151).

O que perguntam, então, as crianças com problemas psíquicos a respeito de suas origens? Como se relacionam com o saber? Essas indagações serão cruciais se quisermos ensinar a elas mais do que comportamentos adequados às suas necessidades, ou mais do que comportamentos visando a uma aprendizagem que contente os adultos, no registro da demanda de aprender.

Perguntar sobre o lugar de onde viemos e o lugar para onde vamos é perguntar sobre a sexualidade e a morte. As produções da cultura são tentativas de respostas para essas questões. Colocar as crianças com problemas psíquicos na escola significa então ajudá-las a encontrar, nessas produções, quer as respostas, ainda que parciais, para as crianças que podem formular a pergunta crucial, quer a possibilidade de construí-la para aquelas que ainda não a formularam. A escola poderia ser bem mais do que um lugar de transmissão de conhecimentos técnicos com métodos especializados e adaptados às crianças com necessidade especiais.

Assim, depois de colocada a perspectiva psicanalítica ao lado dos trabalhos das equipes francesa e brasileira sobre o desejo de aprender e a relação com o saber, vale a pena retomar e ampliar a pergunta colocada pelo ouvinte brasileiro no colóquio mencionado acima: é possível construir, na escola inclusiva de hoje, o ausente ou comprometido desejo de saber de uma criança com problemas psíquicos?

A resposta é: se a escola inclusiva de hoje não for capaz de fazê-lo, teremos que mobilizar educadores, psicanalistas e pesquisadores na direção de trabalhar por sua transformação.

\footnotetext{
6 A referência à distinção entre necessidade de aprender, demanda de aprender e desejo de saber baseia-se na distinção construída por Lacan entre necessidade, demanda e desejo, particularmente no Seminário 5 (Lacan, 1957-58).
} 


\section{REFERÊNCIAS}

Bastos, M. (2003). Inclusão escolar: Um trabalho com professores a partir dos operadores da psicanálise. Dissertação de mestrado em Psicologia Escolar e do Desenvolvimento Humano, Universidade de São Paulo, São Paulo.

Beillerot, J., Bouillet B., Blanchard-Laville, C., \& Mosconi, N. (1989). Inclusão escolar de professores: uma tarefa para a psicanálise? Correio da APPOA, 120, p. 27-33.

Brasil. (1996). Lei n. 9.394, de 20 de dezembro de 1996. Estabelece as diretrizes e bases da educação nacional. Recuperado em 23 jun 2009, em http:// www6.senado.gov.br/legislacao/ListaTextoIntegral. action? $\mathrm{id}=75723$

Centers for Disease Control and Prevention - CDC. (2007). CDC Releases New Data on Autism Spectrum Disorders (ASDs) from Multiple Communities in the United States. Recuperado em 01 out. 2008, em http://www.cdc.gov/od/oc/ media/pressrel/2007/r070208.htm

Colli, F., \& Kupfer, M. C. (Org.). (2005). Travessias: Inclusão escolar. São Paulo: Casa do Psicólogo.

DSM-IV (1995). Manual diagnóstico e estatístico de transtornos mentais. (4a ed). Porto Alegre: Artes Médicas.

Fleitlich-Bilyk, B., \& Goodman, R. (2004). Prevalence of child and adolescent psychiatric disorders in southeast Brazil. Journal of the American Academy of Child and Adolescent Psychiatry, 43(6), 727-734.

Freud, S. (1973). Três ensayos para una teoria sexual. (Tomo II, pp. 1169-1237). (L. L. Ballesteros, Trad.). Madrid: Biblioteca Nueva. (original publicado em 1905).

Gachet, P. F. (2009). La Loi de 2005: Um premier bilan? Conferência pronunciada na Journée d'études de l'INRP, em Lyon [registro oral da conferência]. Recuperado em 15 fev. 2009, em http://www.inrp. $\mathrm{fr} /$ manifestations/formation/handicap-ecole

Gardou, C. (2009). Les situations de handicap dans le processus de scolarisation: Quels grands enjeux? Paris: Odile Jacob.

Kupfer, M. C. (1990). O desejo de saber. Tese de doutorado apresentada ao Instituto de Psicologia da Universidade de São Paulo, São Paulo.
Lacan, J. ([1957-58] 1999). O seminário (Livro 5): As formações do inconsciente. Rio de Janeiro: Jorge Zahar.

Lacan, J. ([1958] 1998). A direção do tratamento e os princípios de seu poder. In J. Lacan. Escritos. Rio de Janeiro: Jorge Zahar.

Lajonquière, L. (2001). Duas notas psicanalíticas sobre as crianças 'com necessidades educativas especiais'. Pro-Posições: Revista da Faculdade de Educação da Unicamp, 12(2-3), 47-59.

Mena, L. F. B. (2000). Inclusões e inclusões: A inclusão simbólica. Psicologia: Ciência e Profissão, 20(1), 30-39.

Oliveira, F. M. G. S. A educação inclusiva: Diferentes olhares. Recuperado em 01 out. 2008, em http:// www.mj.gov.br/conade/arquivos/pps/palestras_ EducacaoInclusiva.ppt

Pechberty, B. (2007). O debate entre o cuidado e a educação: Práticas clínicas atuais. Estilos de Clinica, 12(22), 14-25.

Sayão, Y., \& Leão, S. (2000). Negócio fechado: Mateus vai à escola. In M. C. Kupfer. (Org.). Tratamento e escolarização de crianças com distúrbios globais no desenvolvimento. Salvador: Ágalma.

Recebido: 23/03/2009

Received: 03/23/2009

Aprovado: 04/05/2009 Approved: 05/04/2009 